\title{
Development of Multimedia Interactive Computer-based and Mobile-based Learning: Case Studies in the Learning of Logic
}

\author{
Muhammad Rusli \\ Information System Department \\ STMIK STIKOM Bali \\ Puputan 86, Denpasar-Bali
}

\author{
Anggun Nugroho \\ Computer System Department \\ STMIK STIKOM Bali \\ Puputan 86, Denpasar-Bali
}

\begin{abstract}
This research was the development research, i.e. developing a multimedia interactive learning over a matter of principle, that is, Logic. The learning strategy follows the Merrill's strategy (in Component Display Theory or CDT, especially those related to the rule relation between display), and the principle of animation (pointer animation) in learning via multimedia (multimedia, modality principle, spatial and temporal contiguity). The software of its development using the Authoring tool Adobe Captivate 9. The results of this research were two effective interactive multimedia learning modules (computer-based and mobile-based) that had the quality of good-very good. With the modules, the learner will have the option of learning and be more motivated (via a computer or mobile device) to learn independently repeatable and meaningful, such that the ability of the learner in applying concepts, procedures and basic principles of Logic can be achieved.
\end{abstract}

\section{Keywords}

Multimedia learning, pointer animation, computer-based learning, mobile-based learning

\section{INTRODUCTION}

The development of multimedia technology in the digital era is now strongly support the development of multimedia learning, both computer-based and mobile-based. With its development, both in terms of hardware and software, has allowed the technique and practice of good teaching in conventional classes (face-to-face instruction) can be realized in multimedia learning or learning modules, either computerbased or mobile-based. Therefore, the selection of the authoring tool (software developer multimedia learning) was important in the development of multimedia content learning or e-learning in order to improve the interaction of learners (Khademi et al., 2011). Some aspects to consider in these elections: the ease in learning, using, controlling, designing, and manufacturing (Dağ et al., 2014). Multimedia learning has played an important role in the improvement/enhancement of the learning experience of the learners (Ganesan, 2009; Passerini, 2007). In addition, learning with multimedia can provide satisfaction of higher learning for learners than conventional learning in class (Wang, 2010). A multimedia learning, as part of e-learning, will be effective when in the construction/development to successfully integrate its main elements, namely: the presence of the desired learning objective, content, strategies/methods of learning, and media delivery (Clark, 2008). The effectiveness of multimedia learning may be more increases, when in design and manufacture, also pay attention to accommodating the other aspects, for example: the learners learning style (Clark \&
Mayer, 2008); availability of control facility of learners or multimedia interactivity, which is useful in controlling the cognitive load of learners during a learning process (Tabbers $\&$ de Koeijer, 2010); content type (static/dynamic) which will be presented (Passerini, 2007); and content visualization type (static/animated) (Lin \& Dwyer, 2010).

Related to such matters, in the development of multimedia learning, certainly need to pay attention to the following points: (1) the development of the modern multimedia technologies that are able to support the development/learning with multimedia development faster, interesting and effective, (2) the conditions/criteria that must be met in order for the effectiveness of multimedia learning built/developed is reached, (3) associated with the delivery, the need for media content presentation with animated visualization (pointer animation) can be used in ways that are consistent with how does the human learn (principle of animation in learning via multimedia) (Clark \& Mayer, 2008; Mayer \& Moreno, 2003). This research was the development research, i.e. developing a multimedia interactive learning over a matter of principle, that is, Logic. The learning strategy follows the Merrill's strategy (in Component Display Theory or CDT, especially those related to the rule relation between display), and the principle of animation (pointer animation) in learning via multimedia (multimedia, modality principle, spatial and temporal contiguity) (Clark \& Mayer, 2008).

This research was a further development of the multimedia learning of Java programming built earlier with the same authoring tool, namely Adobe Captivate 9 (Rusli, 2016; Rusli et al., 2017). Development of modules which were now imposed upon different content (material Logic). The results of this development in the form of two learning modules logic with a different type of delivery media, namely computerbased and mobile-based learning modules.

The development of learning modules with 2 different type of delivery were done after getting inspiration from the research results of Nguyen (2015), which concluded that learning online learning as effective compared with learning in the classroom. What about the computer-based and mobile-based learning? Whether it's are also same as effective? At least, for a while with the 2 nd module, learners are expected to be more motivated and have the option of learning independently (via a computer or mobile), repetitive and meaningless such that the ability of the learner in applying concepts, procedures, and basic principles of Logic can be achieved.

Development of multimedia learning applications at 2 different delivery media type is very possible when using the authoring tool adobe captivate 9, by publishing it in a different application file types (extensions file exe and swf). Application file with the extension file exe can be run as a multimedia computer-based learning, and application file with 
extension swf can be run as a multimedia mobile-based learning (after the file be copied on a mobile device, download the swf driver through the play store, and run it).

\section{RESEARCH METHODS}

This research was the development research, namely: developing a multimedia interactive learning for content of logic. The design of the development include the preparation of content framework to be learned, designing the menu of module or flowchart, user interface, and storyboards (Ivers \& Barron, 2010). Learning strategies include: determination of learning objectives, content presentation, practices/exercises, and test (Berkove \& Moore, 2001; Clark, 2008). While the animation (pointer animation) following the rules of animation in learning with multimedia (Clark \& Mayer, 2008), especially about the principle of multimedia (learners learn better from animation and narration [audio] than with just the narration only), the principle modalities (learners learn better from animation and narration [audio] than with animation and text on the screen [Visual]), the principle of spatial contiguity (the learners learn better if the words [texts] is displayed near the related portion of the animation [picture]). The principle of temporal contiguity (the learners learn better when the related portion of the narration and animation are presented at the same time or concurrently rather than consecutively). Based on the reference, methods of research/development described below:

\subsection{Defining the learning objectives}

Learning objectives is represented in a matrix of performance, i.e. so that students are able to understand and apply the concepts, procedures, and principles of Logic.

\subsection{Developing the content framework}

Based on (2.1) was compiled the framework of material/content to be learned. The framework of content includes 3 subjects (proposition logic, deductive reasoning, and predicate logic) with every subject matter accompanied by examples/exercises.

\subsection{Determining the content \& learning strategy}

Based on (2.1) and (2.2) were described the essential and relevant learning content (fig 1) and its learning strategies.

\subsection{Developing the application menu}

Based on (2.3) was developed the outline of the application menu or module menu of multimedia learning (fig 2).

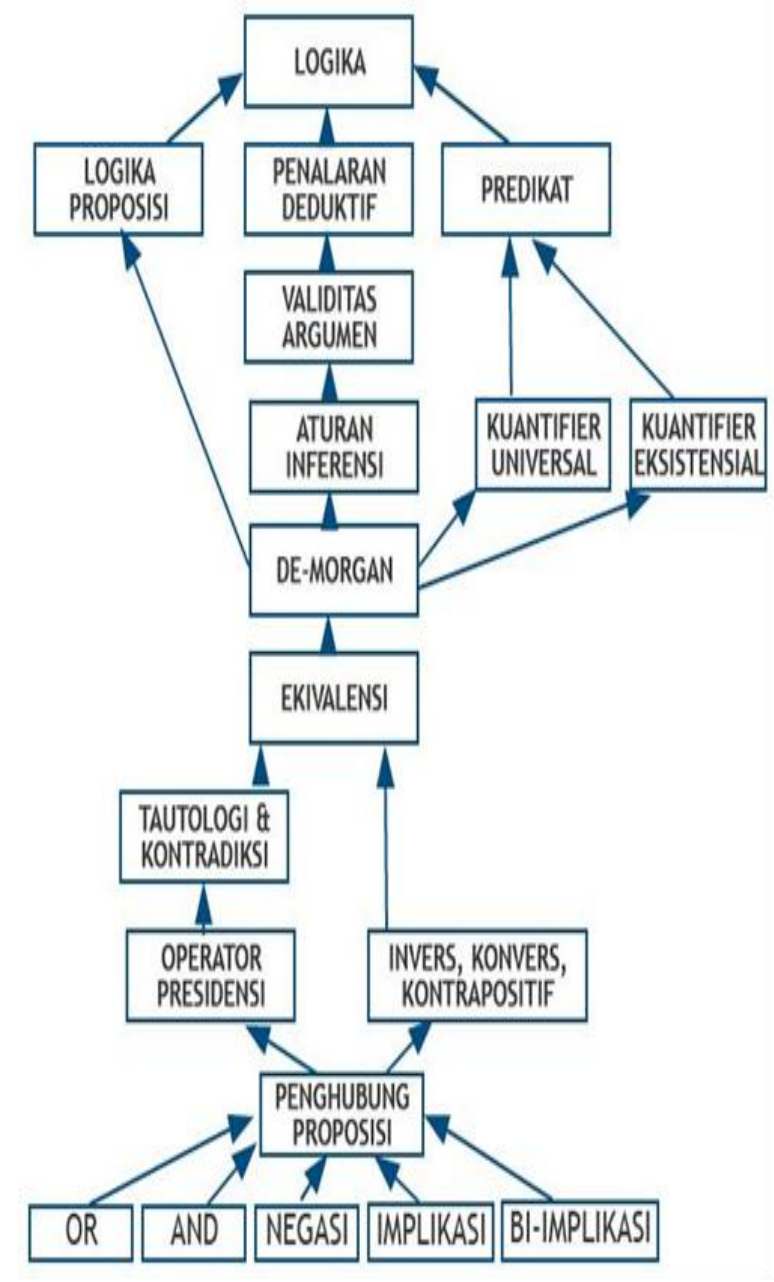

Fig 1: Structure of Logic Content 


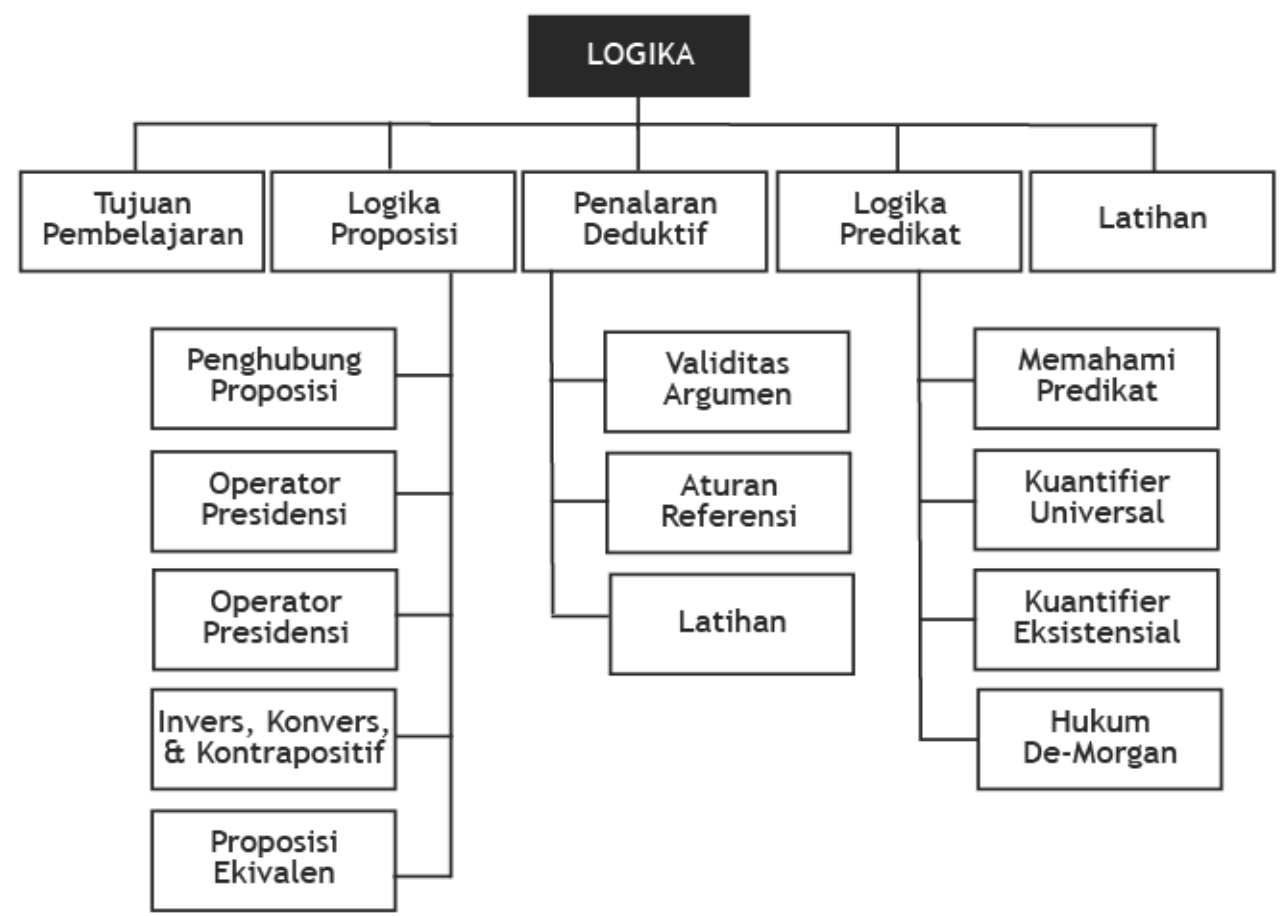

Fig 2: The Outline of Application Menu

\subsection{Designing the user interface}

Based on (2.3) and (2.4) were designed the screen layout or user interface of multimedia learning module.

\subsection{Designing the storyboards}

Based on (2.3) and (2.5) were designed the storyboards for each screen described the multimedia elements (text, pictures/images, animation, narration of voice/text) will be loaded/included.

\subsection{Developing the multimedia learning module}

Based on (2.6) was developed the multimedia learning module of logic content through implementation of authoring tool of Adobe Captivate 9.

\section{RESEARCH RESULT \& DISCUSSION}

\subsection{Research Result}

The results of the research are described below:

\subsubsection{Structure of Content}

The structure of content (fig 1) represents the order/collation of learning units start learning unit lowest up to the highest. Lower learning unit represents as a prerequisite to be able to learn the units of higher learning. Therefore, to be able to master the content of logic, the learners must master first learning units lower/earlier.

\subsubsection{Module Menu}

The module menu represents the outline of flowchart or branch view of application of learning module. Fig 2 showed the outline of learning module application. The module menu can contains the sequence screens/slides presentation show the presentation content from beginning to end with branching/ linking. Each slide in his performance is always accompanied by pointer animation (pointing to a text/image most content) aligned with the appearance of the narrative voice (explanation of the text/image designated by the pointer animation).

\subsubsection{Screen-shot of Application}

\subsubsection{Example of module menu}

Fig 3 and fig 4 represent the screen-shot options main menu modules that include: learning objectives, logic of the proposition, deductive reasoning, predicate of logic, and exercise (desktop and mobile).

\subsubsection{Example of screen-shot with pointer animation and narration}

Fig 5 and fig 6 represent an example screen-shot pointer animation accompanied the narrative voice (explaining the text/image pointer, designated in the desktop and mobile device).

\subsubsection{Example screen-shot of an exercise}

Fig 7 and fig 8 represent screen-shot of an exercise (desktop and mobile device). 


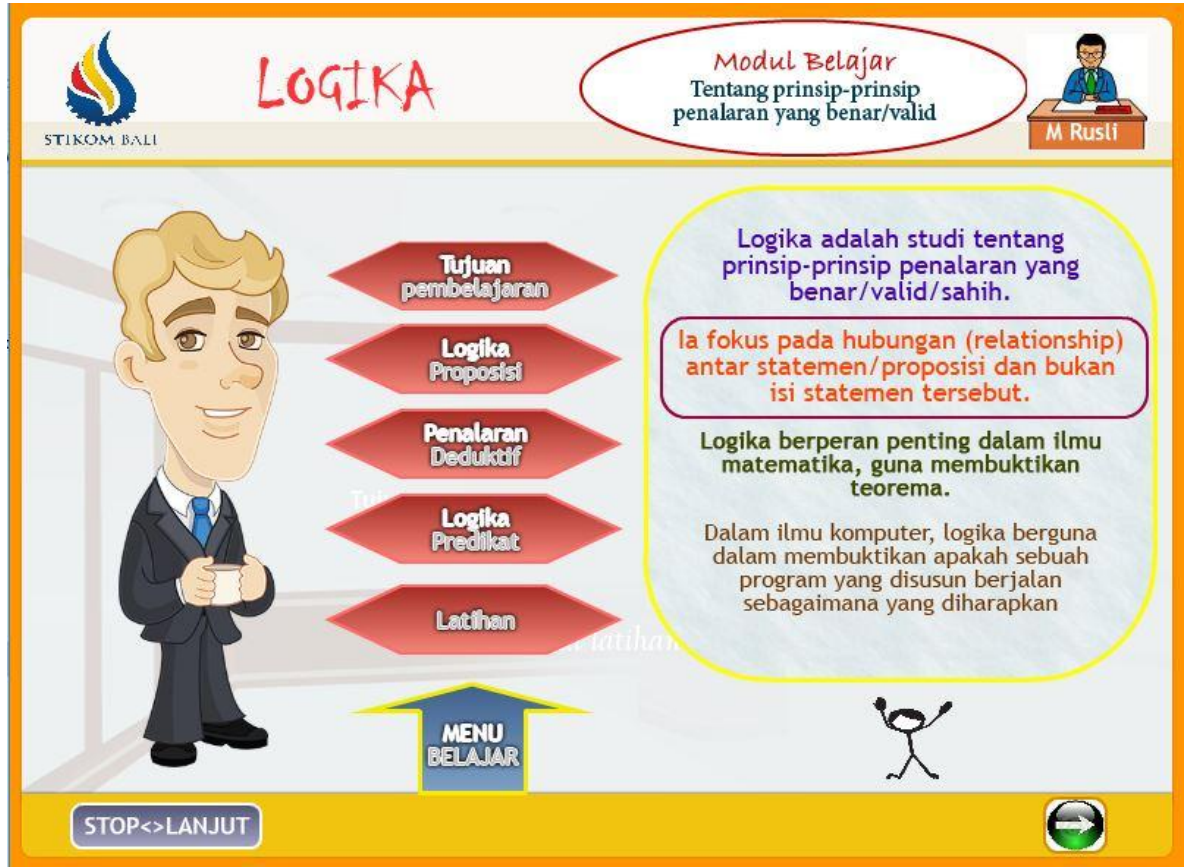

Fig 3: Screen-shot of main menu with pointer animation on desktop

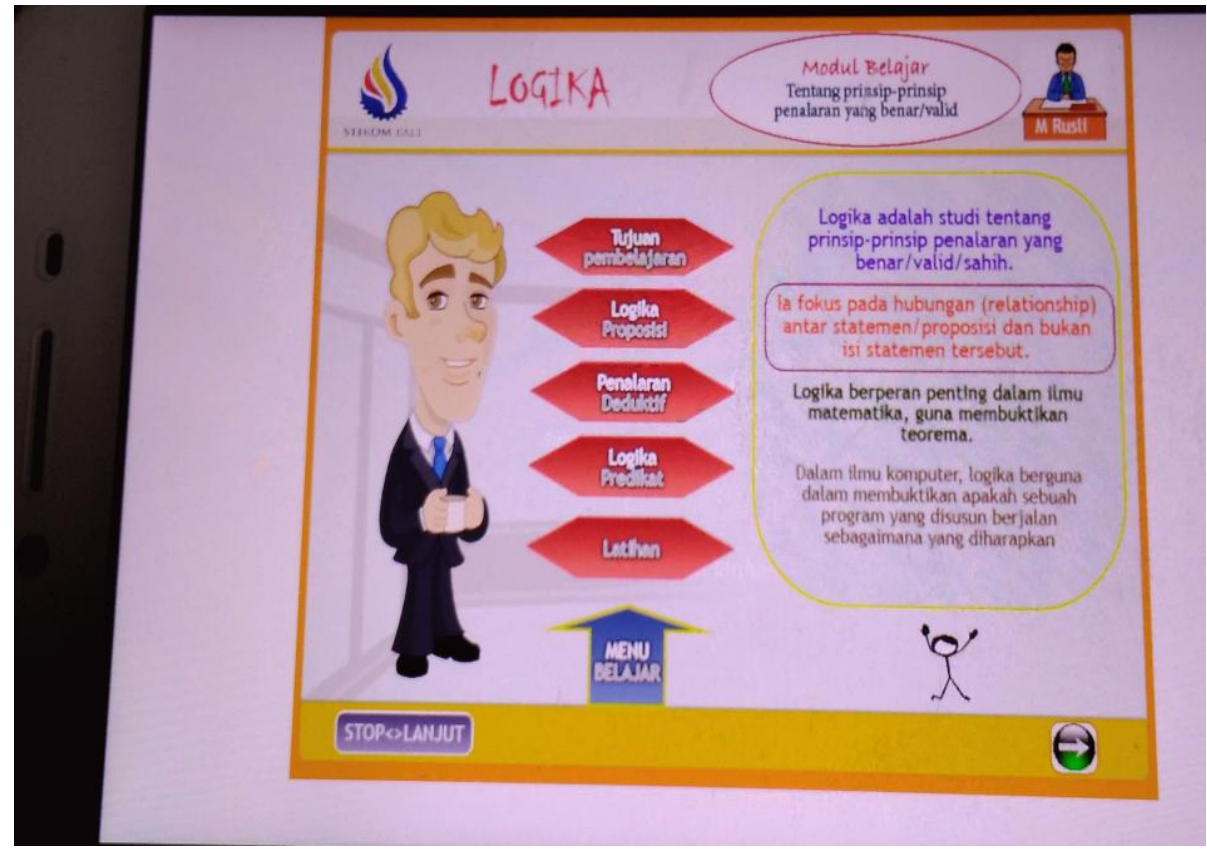

Fig 4: Screen-shot likes fig 3 on mobile device

\subsubsection{Evaluation of Usability}

Usability aspects of a multimedia learning module (MLM) need to be evaluated. Nasir et al. (2012) provided the guidance over such matters through the quality assessment instrument (its reliability has been tested). There are 10 items critical quality indicators with $1-5$ scales $(1=$ poor, $2=$ average, $3=$ good, $4=$ very good, $5=$ excellent). The 10 critical indicators include: 1> Learning Objectives (LO) are clearly stated, 2> Language is appropriate to the target audience, 3> Content is accurate and factual, 4> Content meets objectives, 5> Clear instructions are available and how to use the content $6>$ Content is easy to understand, 7> MLM is interactive, $8>$ The use of the media is appropriate, 9> Interface is user-friendly, and 10> MLM is sensitves to the gender and socio-cultural factors. Based on the data results of quality indicator instrument of 3 respondents (clinical category) who originated from lectures, overall the retrieved value or score as follows: first respondent provided a score of 3; Second respondent provided a score of 4; and third respondent provided a score of 4 . So the evaluation result of the usability of two MLM (desktop and mobile learning) has a value of average $=3.7$ or has the quality of good-very good. 


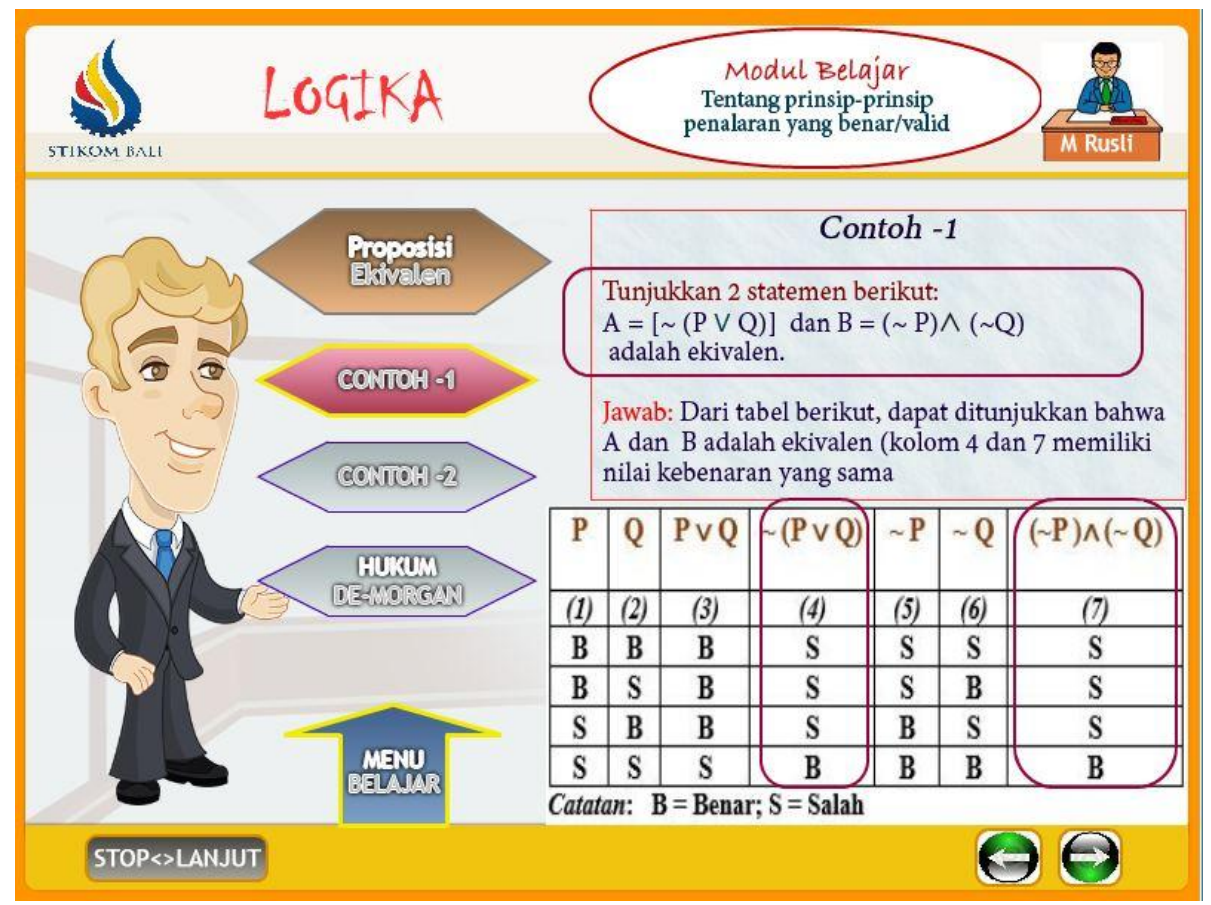

Fig 5: Screen-shot of pointer animation and narrative voice on desktop

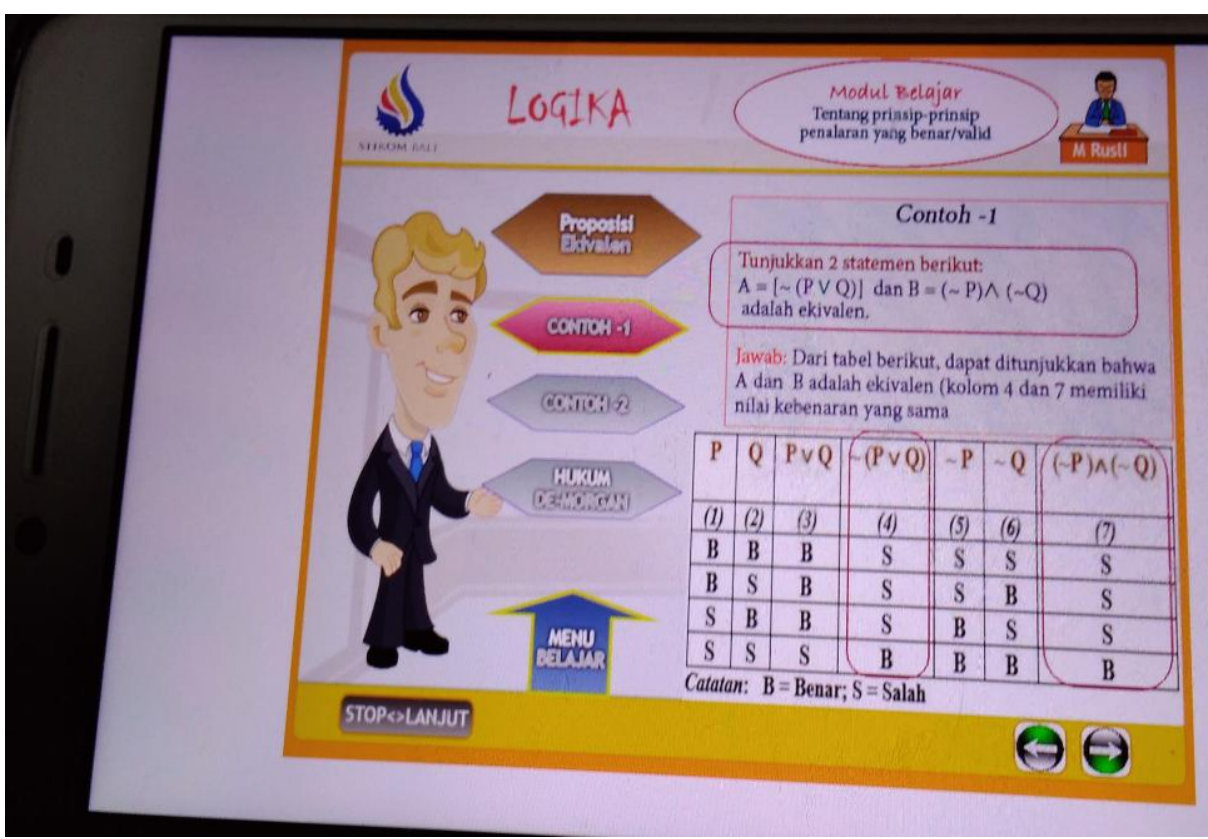

Fig 6: Screen-shot likes fig 5 on mobile device. 


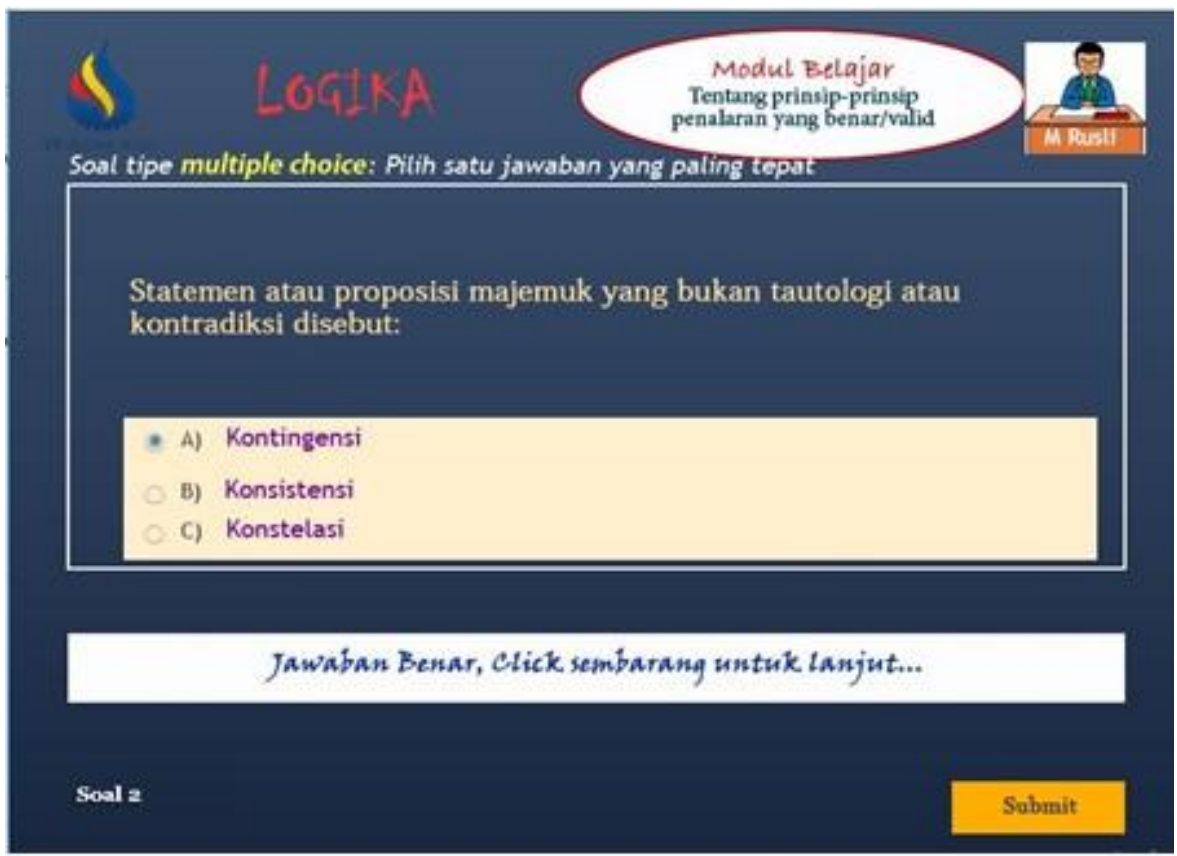

Fig 7: Screen-shot of an exercise on desktop

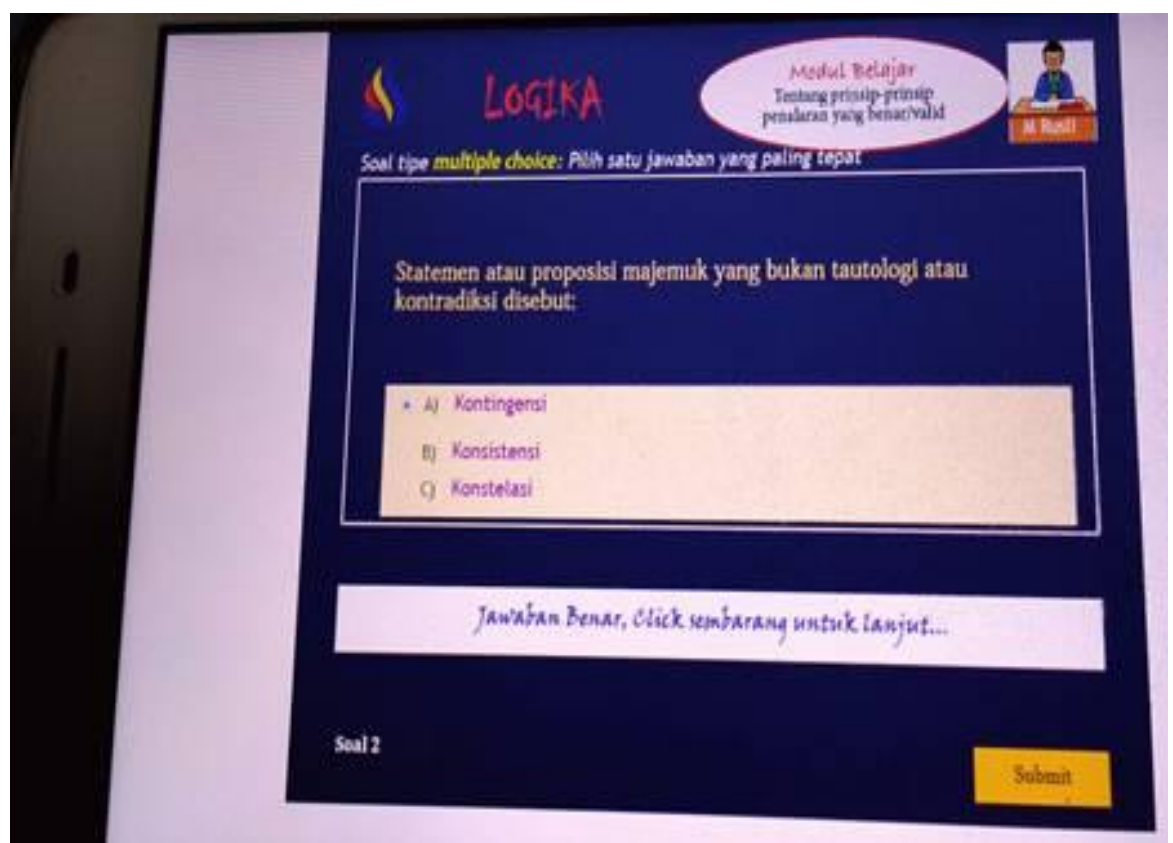

Fig 8: Screen shot likes fig 7 on mobile device

\subsection{Discussion}

There are some requirements that important and deserves to be met in order to get an effective multimedia learning, namely: the presence of learning objectives, content, instructional strategies, delivery media, and also can accommodate the learners learning style, provide the multimedia interactivity (learner-controlled), and adhere to the principle of the rule of the animation. So then, the availability of authoring tools that fast in support of development (easy in learning, using, controlling, designing and implementing it) is very needed. The selection of Adobe Captivate 9 in the implementation of the development of multimedia learning of Logic was well-grounded in meets these criteria, in particular those related to development of an effective multimedia learning with various type of publish (desktop, web, and mobile device).

Hence, a multimedia learning module of Logic as the implementation results with Adobe Captivate 9, can be published and run on a PC (computer-based) and mobile device (mobile-based).

\section{CONCLUSION \& SUGGESTION}

Interactive multimedia learning module of logic content which met the minimum requirements/characteristics as an effective multimedia computer-based and mobile-based learning have been developed and had the quality of goodvery good. With the modules, the learner will have the option of learning and be more motivated (via a computer or mobile devices) to learn independently repeatable and meaningful, 
such that the ability of the learner in applying concepts, procedures and basic principles of Logic can be achieved. Nevertheless, empirically, the effectiveness of multimedia learning modules towards the learning results still need to be tested further in the next research.

\section{ACKNOWLEDGMENTS}

We thank to the Ministry of RisTekDikTi for the research grants over the years 2017 through a scheme of PPT, Coordinator of KOPERTIS VIII (Bali, NTB, NTT), and the management of STIKOM Bali over aid, attention and cooperation.

\section{REFERENCES}

[1] Berkove, N. \& Moore, B. 2001. Component Display Theory. Dalam K.L. Medsker \& K.M. Holdsworth. Models and Strategies for Training Design. Silver Spring, MD: International Society for Performance Improvement.

[2] Clark, R.C. 2008. Developing Technical Training: A Structured Approach for Developing Classroom and Computer-Based Instructional Materials. Third Edition. San Francisco: John Wiley \& Sons, Inc.

[3] Clark, R.C. \& Mayer, R.E. 2008. E-Learning and The Science Of Instruction. Second Edition. San Francisco: In Print of Wiley.

[4] Dağ, F., Durdu, L. \& Gerdan, S. 2014. Evaluation of Educational Authoring Tools for Teachers stressing of Perceived Usability Features. Procedia - Social and Behavioral Sciences, 116, 888- 901.

[5] Ivers, K.S \& Barron, A.E. 2010. Multimedia Projects in Education: Designing, Producing, and Assessing. Fourth Edition. Santa Barbara, California: Libraries Unlimited.

[6] Khademi, M., Haghshenas, M. \& Kabir, H. 2011. A Review On Authoring Tools. 5th International Conference on Distance Learning and Education. IPCSIT vol.12. Singapore. IACSIT Press.
[7] Lin, H. \& Dwyer, F. M. 2010. The Effect of Static and Animated Visualization: a Perspective of Instructional Effectiveness and efficiency. Educational Technology, Research and Development, 58, 155-174.

[8] Mayer, R. E. \& Moreno, R. 2003. Nine Ways to Reduce Cognitive Load in Multimedia Learning. Educational Psychologist, 38(1), 43-52.

[9] Nasir, S.J.A., Asirvatham, D., \& Khalid, H.H.M. 2012. Quality Framework for Assessment of Multimedia Learning Materials Version 1.0. Procedia-Social and Behavioral Sciences 67, 571-579.

[10] Nguyen, T. 2015. The Effectiveness of Online Learning: Beyond No Significant Difference and Future Horizons. Merlot Journal of Online Learning and Teaching, 11(2), 309-319.

[11] Passerini, K. 2007. Performance and Behavioral Outcomes in Technology-Supported Learning: The Role of Interactive Multimedia. Journal of Educational Multimedia and Hypermedia, 16(2), 183-211.

[12] Rusli, M. 2016. Implementasi Adobe Captivate dalam Pengembangan Multimedia Pembelajaran yang Efektif: Studi Kasus Pembelajaran Pemrograman Java. Prosiding Seminar Nasional Inovasi Pendidikan di Era Big Data dan Aspek Psikologinya. Pascasarjana, Universitas Negeri Malang.

[13] Rusli, M. \& Rinartha, I.K. 2017. The Effect of Animation in Multimedia Computer-Based Learning and Learning Style to The Learning Results. Turkish Online Journal of Distance Education, 18(4), 177-190.

[14] Tabbers, H.K. \& de Koeijer, B. 2010. Learner Control in Animated Multimedia Instructions. Instructional Science, 38, 441-453.

[15] Wang, T.J. 2010. Educational Benefits of Multimedia Skills Training; TechTrends, 54(1), 47-57. 